\title{
Suspended hydration and loss of freezable water in cement pastes exposed to $90 \%$ relative humidity
}

\author{
by \\ K.A. Snyder and D.P. Bentz \\ Building and Fire Research Laboratory \\ National Institute of Standards and Technology \\ Gaithersburg, MD 20899 USA
}

Reprinted from Cement and Concrete Research, Vol. 34, No. 11, 2045-2056, November 2004.

NOTE: This paper is a contribution of the National Institute of Standards and Technology and is not subject to copyright. 


\title{
Suspended hydration and loss of freezable water in cement pastes exposed to $90 \%$ relative humidity
}

\author{
K.A. Snyder*, D.P. Bentz \\ Materials and Construction Research Division, Building and Fire Research Laboratory, National Institute of Standards and Technology, \\ Gaithersburg, MD 20899, USA \\ Received 12 November 2003; accepted 3 March 2004
}

\begin{abstract}
Degree of hydration (DOH) and differential scanning calorimetry (DSC) measurements are used to characterize the effect of early exposure to a $90 \%$ relative humidity $(\mathrm{RH})$ environment on cement paste hydration. Early exposure to a $90 \% \mathrm{RH}$ environment can lead to the consumption of freezable water and altered microstructural development. The minimum duration of $100 \%$ RH curing required to eliminate the effects of an unsaturated environment on microstructural development coincides with the appearance of a DSC peak near $-30{ }^{\circ} \mathrm{C}$ that occurs in the range 1-14 days for the pastes studied. The Jennings colloidal microstructural model is used to argue that the $-30{ }^{\circ} \mathrm{C}$ peak coincides with the cessation of capillary pore percolation. Alternatively, all samples cured under $100 \% \mathrm{RH}$ conditions for 7 days prior to $90 \%$ $\mathrm{RH}$ exposure hydrated at the same rate as those continuously exposed to $100 \% \mathrm{RH}$. The application of these results to the formulation of separate curing practices for durability and strength is discussed.

Published by Elsevier Ltd.
\end{abstract}

Keywords: Calorimetry; Curing; Degree of Hydration (Nominated); Humidity; Microstructure

\section{Introduction}

Cement paste, the binding phase of concrete, is primarily a calcium silicate hydrate $(\mathrm{C}-\mathrm{S}-\mathrm{H})$ that develops its interconnected solid structure from a chemical reaction that consumes approximately $0.25 \mathrm{~g}$ water per $\mathrm{g}$ cement, with an additional $0.15 \mathrm{~g}$ water per $\mathrm{g}$ cement incorporated into the hydrated gel structure [1]. Although the majority of the hydration reaction takes place during the first month, the hydration during the first few days has the greatest effect on the overall performance of the concrete. It is during this initial hydration that the availability of water is critical to proper $\mathrm{C}-\mathrm{S}-\mathrm{H}$ formation. Most concrete elements are made with sufficient water for complete hydration and can therefore hydrate sufficiently under sealed conditions. When evaporation from the surface occurs, however, moisture transport through the concrete may be insufficient to replace lost water from either the environment or the interior of the concrete. Failure to maintain saturation at the surface can have detrimental effects on concrete surface properties and, possibly, on the overall concrete structural element perfor-

* Corresponding author.

E-mail address: kenneth.snyder@nist.gov (K.A. Snyder). mance. Industrial curing practices incorporate a number of methods for either maintaining a humid environment at the concrete surface or using chemical or physical barriers to minimize moisture loss [2].

Because proper curing practices constitute a financial burden that is proportional to their duration, and because curing beyond a certain period will have no effect upon concrete performance, an optimum curing practice is sought. The jdeal curing regimen maintains saturation within the concrete surface for the shortest period of time, such that additional effort would have negligible effects on the desired concrete properties. The ACI Manual of Practice [2] recommends 7 days curing for concretes made with Type 1 cement, regardless of the water-cement ratio. Moreover, "Natural curing from rain, mist, high humidity, ... regarded as sufficient to provide ample curing..." (ACI 308-92, Section 2.10) may be considered, although sufficiently high humidity is neither defined nor a lower limit established.

The more important question, however, is the combined effects of curing duration and the level of concrete saturation required for normal hydration with respect to saturated conditions ( $100 \%$ relative humidity $(\mathrm{RH})$ ). The minimum sufficient level of saturation is not known because the 
effects of exposure to environments below $100 \% \mathrm{RH}$ have not been sufficiently quantified, inhibiting the development of rational curing procedures.

A number of previous studies have attempted to quantify the effect of environmental $\mathrm{RH}$ on portland cement paste hyd ation. In the experiment reported by Powers [3], which quoed previous results of Gause and Tucker [4], fresh cement paste was placed into sealed glass jars. Periodically, the jars were opened, and the $\mathrm{RH}$ was measured in the air space over the paste. The measured $\mathrm{RH}$ decreased monotoni vally, terminating at a value in the range of $80-90 \%$, depending upon the initial water-cement $(w / c)$ mass ratio. As c:ement paste hydrated, the chemical reaction consumed the available free water. When all the surface water had disappeared, continued hydration reduced the $\mathrm{RH}$ inside the jar. At the same time, the reaction products were filling the initially water-filled pore space, decreasing the effective pore diameters and reducing the $\mathrm{RH}$ at which the pores could still remain saturated via the Kelvin-Laplace effect [5]. Within a sealed system, there is competition between the decreasing $\mathrm{RH}$ due to water consumption and the decrease in the equilibrium $\mathrm{RH}$ due to pore size reduction. Based on the results reported by Powers [3], the rate of $\mathrm{RH}$ reduction due to reaction was greater than the reduction in equilibrium $\mathrm{RH}$ environment due to pore size reduction, and the reaction terminated because the pores were unable to remisin saturated.

In a related experiment, Parrott et al. [6] reported continued hydration for $0.59 \mathrm{w} / \mathrm{c}$ pastes at relative humidities as low as $55 \%$. Their specimens were $3-\mathrm{mm}$ thick slices cut from the middle of a prism after two days of hydjation. Coming from the middle of the prism, the samoles were initially able to draw water from the surrour ding paste. As such, the samples represented (virtually) s:aturated samples at the time of exposure. The degree of hydration (DOH) was measured after 14 and 90 days of exposure to various relative humidities, and the values wer: compared with the DOH of continuously saturated specimens. The ratio $R$ of the $\mathrm{DOH}$ for a sample hydrating at a relative humidity $\phi$ to the $\mathrm{DOH}$ of a sample hydrating under saturated conditions was approximated by a power law relationship [6]

$R=\left(\frac{\phi-0.55}{0.45}\right)^{4}$

The ratio $R$ for values of $\phi$ less than 0.55 is, by definition, zero. Using Eq. (1), the rate of hydration for expcisure to a $90 \% \mathrm{RH}$ environment is 0.37 times that for a continuously saturated specimen.

Lnfortunately, neither experiment demonstrates the full complexity of the effects that an unsaturated environment $(<100 \% \mathrm{RH})$ during initial hydration can have on microstructural development. The rate of hydration in an unsaturated environment will depend upon the age of the cement paste: at the time of exposure, and the time required for the specimen to reach equilibrium with the unsaturated environment. A young specimen having large capillary pores and exposed to an unsaturated environment could lose sufficient free water through evaporation that the rate of hydration at the surface could virtually cease. Conversely, a specimen initially hydrating under saturated conditions for a sufficiently long time would contain pores small enough that water would not evaporate into an unsaturated environment, and the specimen could continue to hydrate in an unsaturated environment at a rate nearly equal to saturated conditions. Therefore, the rate of hydration for a specimen exposed to an unsaturated environment should depend, in part, upon the duration of the initial period of hydration under saturated conditions.

To test this theory, an experimental plan was developed to study the hydration and microstructural development in specimens exposed to an unsaturated environment. In the experiment, the unsaturated environment consisted of $90 \%$ $\mathrm{RH}$ air at $25{ }^{\circ} \mathrm{C}$. A $90 \% \mathrm{RH}$ environment was chosen because the common assumption, based largely on Powers [3], is that hydration continues indefinitely in a $90 \% \mathrm{RH}$ environment. Moreover, $90 \% \mathrm{RH}$ could be considered as sufficiently high humidity for use as natural curing.

Thin cement paste specimens were initially exposed to a $100 \%$ RH environment. After either 6 or $12 \mathrm{~h}$, or 3 or 7 days of exposure to a $100 \% \mathrm{RH}$, each specimen was moved to a $90 \% \mathrm{RH}$ environment. DOH measurements from these exposed specimens, as a function of time, were compared to with corresponding values from samples continuously exposed to $100 \% \mathrm{RH}$. Differential scanning calorimetry (DSC) measurements were used to detect freezable water within a specimen as a function of time.

Arguably, a $100 \% \mathrm{RH}$ exposure is not identical to moist curing. A $100 \%$ RH environment can, however, supply water to surface pores as needed, provided that the rate of vapor transport through the atmosphere is faster than the rate of water consumption due to hydration. Furthermore, due to the ionic strength of the pore fluid, the pore fluid is likely in equilibrium with a $95 \%$ to $97 \% \mathrm{RH}$ environment. Therefore, it is likely that the $100 \% \mathrm{RH}$ environment will form a film of liquid over the surface of the paste. Moreover, results will show that the rate of hydration for the specimens exposed to $100 \% \mathrm{RH}$ was identical, within experimental error, to the independent measurements made on cement pastes in contact with water.

A similar experiment with this one has been performed by Bager [7]. In that experiment, specimens were exposed to $58 \% \mathrm{RH}$ after water curing for $2,3,7$, and 10 days. Bager [7] used mercury intrusion porosimetry to characterize the microstructure, DSC to determine the total freezable water, and electrical conductivity and permeability measurements to characterize the effect of exposure on transport. The experiment reported herein extends the work of Bager [7] by using the temperature-dependent DSC data to characterize the developing microstructure and the DOH to characterize the macroscopic effects, both as a function of time. In 
this way, the time-dependent effects of early exposure can be studied in more detail.

\section{Experiment}

The molds for the cement paste specimens were made frorn 1.6-mm-thick (nominally $1 / 16 \mathrm{in}$.) polytetrafluoroethylene (PTFE) sheets. For each mold, two pieces, each $150 \times 160 \mathrm{~mm}$, were cut from the PTFE sheet. A mechanical punch was used to create twenty-three $25-\mathrm{mm}$ diameter holes through one of the pieces. The two pieces were then adhered to one another using a room temperature vulcanizing (RTV) adhesive, forming a mold for 23 cement paste disk specimens, each $1.6-\mathrm{mm}$ thick. A mold was assembled for each initial $100 \% \mathrm{RH}$ curing period, plus one mold for the specimens remaining indefinitely in the $100 \% \mathrm{RH}$ environment.

Cement paste specimens having $w / c$ mass ratios of 0.30 , 0.40 , and 0.50 were prepared from the Cement and Concrete Reference Laboratory (CCRL) proficiency sample portland cement number 116 [8] and distilled water. Table 1 shows the cement chemical composition. For each experiment, at a given $w / c$, the cement and water were equilibrated at $25^{\circ} \mathrm{C}$, then combined in a resealable plastic bag and kneaded by hand, with the aid of a vibration table, for a period of $5 \mathrm{~min}$. The mixed paste was spread over each PTFE mold using a small strip of PTFE as a trowel. The cast specimens were placed onto a shelf inside a sealed glass container, the bottom of which contained distilled water to maintain a $100 \% \mathrm{RH}$ environment. The glass container was located in an environmental chamber maintained at $25^{\circ} \mathrm{C}$. To minimize the effect of bleeding, the $0.5 \mathrm{w} / \mathrm{c}$ samples were inverted every $15 \mathrm{~min}$ for the first hour, every $30 \mathrm{~min}$ for the second hour, and every hour for the next $4 \mathrm{~h}$.

For each w/c value, four initial $100 \%$ RH curing periods were investigated: 6 and 12 hours and 3 and 7 days. Five PTFE molds were filled with cement paste at the same time and were then placed into the glass container and exposed to $100 \% \mathrm{RH}$ at $25^{\circ} \mathrm{C}$. When a mold was removed from the glasis container, the two adhered PTFE sheets were pried apart to expose both sides of the 23 paste disks remaining in the perforated sheet. The PTFE sheet containing the 23 paste

Table 1

Chemical composition of the CCRL proficiency sample portland cement number 116

Oxide

Mass \% disks was then placed into a glove box having an atmosphere of $25^{\circ} \mathrm{C}$ and $90 \% \mathrm{RH}$ air and equipped with a fan for circulation. To prevent carbonation, the glove box was supplied with $\mathrm{CO}_{2}$-free air at a rate of three glove box volumes per day.

The humidity and temperature within the glove box were maintained using electronic feedback controllers with thermocouple temperature and semiconductor humidity sensors. The humidity sensor was standardized using a commercial two-pressure humidity generator based upon the device developed at NIST [9]. The electronic controllers maintained the temperature to within $0.5^{\circ} \mathrm{C}$ and the $\mathrm{RH}$ to within $0.5 \%$. However, when the 6- and 12-h specimens were first placed into the chamber, the $\mathrm{RH}$ would increase and subsequently return to $90 \% \mathrm{RH}$ after a few hours.

Periodically, specimens in the glove box were removed from the PTFE mold for measurements of DOH and freezable water content. The $\mathrm{DOH}$ was determined by mass loss on ignition between 105 and $950^{\circ} \mathrm{C}$. The cement paste disks were first ground using a mortar and pestle, and then flushed with a volume of methyl alcohol approximately equal to five times the sample volume. The ground and flushed samples were placed into a $105{ }^{\circ} \mathrm{C}$ vented oven overnight and were subsequently heated to $950{ }^{\circ} \mathrm{C}$ in a box furnace for at least $3 \mathrm{~h}$. The $\mathrm{DOH}$ was determined from the ultimate loss on ignition ( $0.235 \mathrm{gm} \mathrm{H}_{2} \mathrm{O} / \mathrm{gm}$ cement) for a completely hydrated paste using the technique described by Powers [10].

A qualitative measure of freezable water was made using a differential scanning calorimeter (DSC). Samples having masses ranging from 50 to $90 \mathrm{mg}$ were taken from the cast paste disks. A DSC scan consisted of three steps: equilibrate the sample at a temperature of $-5{ }^{\circ} \mathrm{C}$, equilibrate the sample at a temperature of $+5{ }^{\circ} \mathrm{C}$, and scan from +5 to $-60^{\circ} \mathrm{C}$ at a rate of $-0.5^{\circ} \mathrm{C} / \mathrm{min}$. (Equilibrating at $-5^{\circ} \mathrm{C}$ ensured repeatable results.) This scan rate was chosen because it is reasonably slow [11], and the rate of cooling does not change the estimated volume of supercooled ice formation [12]. In addition, this rate had the practical advantage of allowing for multiple measurements in a single day.

The DSC measurements were used to monitor the presence of water and not as a means of performing cryoporometry. Quantitative cryoporometry relies on the melting scan [13], and the results can be used to estimate the pore size distribution using the Gibbs-Thomson equation [14]. Cryoporometry studies of cement paste have revealed a unimodal pore size distribution (a single wide "hump") over the entire freezing temperature range [15]. By comparison, during freezing, the ice front penetrates the largest pores first, then the progressively smaller pores as the temperature decreases, analogous to mercury intrusion porosimetry. Therefore, any localized peaks that may appear during a DSC freezing scan must be due to reservoirs composed of relatively large pores that are completely surrounded by passages composed of smaller pores. 


\section{Results}

The experimental results are presented in two groups: the DOH and the DSC data. The DOH data are discussed first because their interpretation and relationship to concrete field performance are straightforward. The DSC data, although more complex, are only analyzed qualitatively to gain additional insight into the DOH results and to study microstructural development.

Herein, the samples are referred to by their watercement ratios $(w / c)$ and their duration of initial exposure to the $100 \% \mathrm{RH}$ environment. For example, the 3-day samples are those that were exposed to the $100 \% \mathrm{RH}$ environment for 3 days prior to $90 \%$ RH exposure. Continuous exposure to $100 \% \mathrm{RH}$ is referred to as a saturated water vapor exposure (SWVE). Conversely, exposure to $90 \% \mathrm{RH}$ is referred to as an unsaturated water vapor exposure (UWVE).

\subsection{Degree of hydration}

The DOH $(\alpha)$ data are plotted in Figs. 1-3 for each w/c value. In each figure, there are four sets of data conesponding to the four curing periods at $100 \% \mathrm{RH}$ before subsequent exposure to $90 \% \mathrm{RH}$. Measurements were performed in duplicate pairs, and each datum is plotted on the figure. In many cases, the difference between the measured values was so small that the symbols overlap one another. Additionally, the uncertainty in the individual measurements was sufficiently small, typically less than $2 \%$, that the presence of error bars in the figure would have been. obscured by the datum symbol.

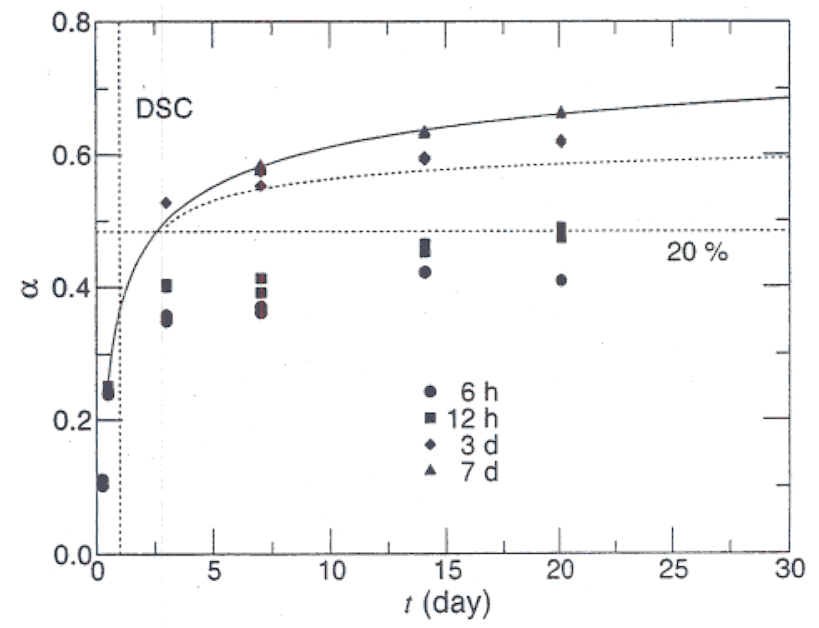

Fig. 1. Degree of hydration $\alpha$ versus time $t$ since mixing for $0.30 \mathrm{w} / \mathrm{c}$ pastes exposed to $90 \% \mathrm{RH}$ after curing at $100 \% \mathrm{RH}$ for $6 \mathrm{~h}, 12 \mathrm{~h}, 3 \mathrm{~d}$, and $7 \mathrm{~d}$. The solid curve represents the degree of hydration for a continuously saturated specinen, and the dashed curve represents the degree of hydration for a senlad specimen. The horizontal dashed line labeled $20 \%$ refers to the capilinry porosity as estimated from Eq. (2). The vertical dashed line litkeled DSC, denotes the age at which the $-30^{\circ} \mathrm{C}$ peak first appears.

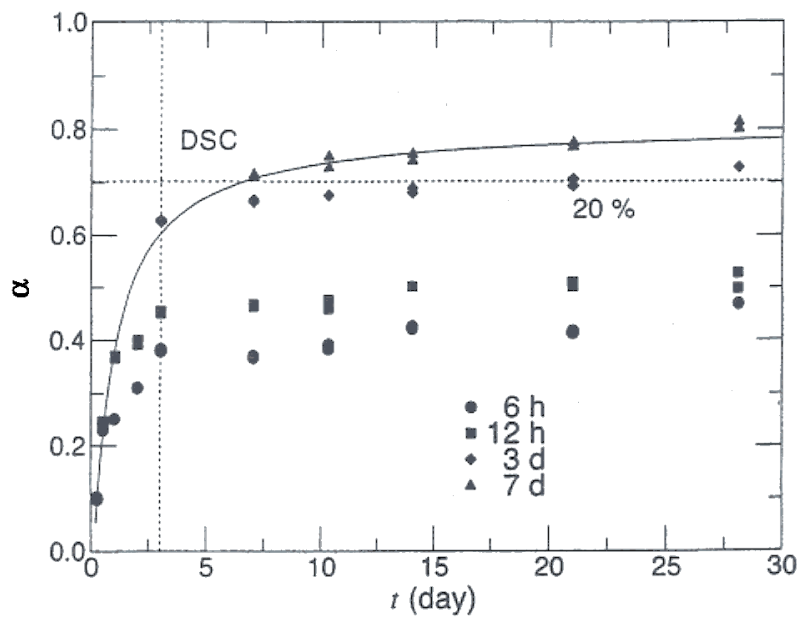

Fig. 2. Degree of hydration $\alpha$ versus time $t$ since mixing for $0.40 \mathrm{w} / \mathrm{c}$ pastes exposed to $90 \% \mathrm{RH}$ after curing at $100 \% \mathrm{RH}$ for $6 \mathrm{~h}, 12 \mathrm{~h}, 3 \mathrm{~d}$, and $7 \mathrm{~d}$. The solid curve represents the degree of hydration for a continuously saturated specimen. The horizontal dashed line labeled $20 \%$ refers to the capillary porosity as estimated from Eq. (2). The vertical dashed line labeled DSC denotes the age at which the $-30^{\circ} \mathrm{C}$ peak first appears.

In addition to the measured $\mathrm{DOH}$, in each figure, there appears a solid curve, a horizontal dashed line, and a vertical dashed line. The solid curve is the DOH for the SWVE specimens. The curve represents a best fit using a parabolic-hyperbolic equation [16-18], and the individual data have been omitted for clarity. This curve was corroborated by independent experiments using calorimetry on the same cement at the same $w / c$ values $[19,20]$. The horizontal dashed line labeled " $20 \%$ " indicates the DOH at which the estimated capillary porosity is $20 \%$, and the capillary pores are assumed to be no longer percolated. The criterion of $20 \%$ capillary porosity was chosen as a compromise

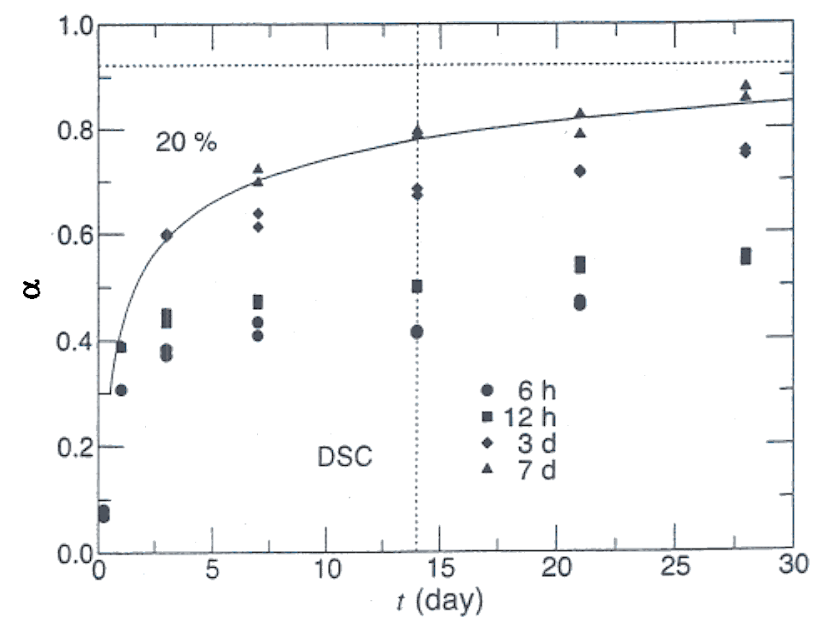

Fig. 3. Degree of hydration $\alpha$ versus time $t$ since mixing for $0.50 \mathrm{w} / \mathrm{c}$ pastes exposed to $90 \% \mathrm{RH}$ after curing at $100 \% \mathrm{RH}$ for $6 \mathrm{~h}, 12 \mathrm{~h}, 3 \mathrm{~d}$, and $7 \mathrm{~d}$. The solid curve represents the degree of hydration for a continuously saturated specimen. The horizontal dashed line labeled $20 \%$ refers to the capillary porosity as estimated from Eq. (2). The vertical dashed line labeled DSC denotes the age at which the $-30^{\circ} \mathrm{C}$ peak first appears. 


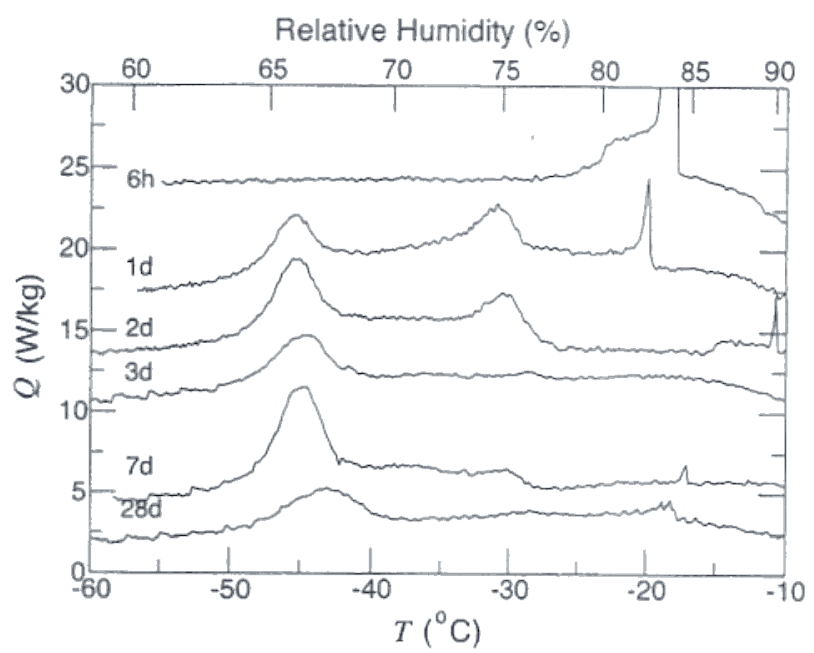

Fig. 4. Freezable water, evident as heat flow (W/kg) from the sample, as a function of age for a $0.30 \mathrm{w} / \mathrm{c}$ cement paste cured at $100 \% \mathrm{RH}$. The data labeis indicate the age of the specimen since the time of casting. Individual curves are offset for comparison purposes.

among published values that range from $18 \%$ to over $22 \%$ [21-23]. The corresponding $\mathrm{DOH} \alpha$ at which the porosity $\theta$ equals 0.20 can be estimated using an equation that is based upon the approach of Young and Hansen [24] and modified to account for multiple clinker phases:

$\theta=1-\frac{1+1.15 \alpha}{1+3.15(w / c)}$

The vertical dashed line labeled "DSC" denotes the age when the DSC freezing peak at $-30{ }^{\circ} \mathrm{C}$ first appears in SWVE samples.

In Fig. 1, for the $0.30 \mathrm{w} / \mathrm{c}$ specimens, there is a second dashed curve just below the solid curve. This second curve is the $\mathrm{DOH}$ for a specimen in which the fresh paste is immediately placed inside a sealed container with no additional water (sealed specimen). This curve was generated from data reported elsewhere $[19,20]$. The curve for the sealed specimens is not visible for the 0.40 and the $0.50 \mathrm{w} / \mathrm{c}$ in Figs. 2 and 3 because it overlaps the solid curve. At these larger values of w/c, the initial volume of water within the specimen is sufficient to hydrate the specimen at a rate indistinguishable from a saturated specimen for at least 28 days.

As can be seen in Figs. 1-3, for all three w/c values, the 6- and 12-h specimens continue to hydrate for the first 2 to 3 days, and then appear to almost cease hydrating. During the initial 2- to 3-day exposure to $90 \% \mathrm{RH}$, the specimens evaporate free water and come to equilibrium with the $90 \%$ $\mathrm{RH}$ environment. This result is dramatic, given that a $90 \%$ $\mathrm{RH}$ exposure is not typically considered severe.

The 3- and 7-day specimens exhibit different behaviors from the 6- and 12-h specimens. For all three values of $\mathrm{w} / \mathrm{c}$, the UWVE 7-day specimens continue to hydrate at a rate indistinguishable from SWVE specimen. Although the 3-day specimens continue to hydrate, their rate of hydration is less than that of the SWVE specimens. Of all the 3-day specimens, only the $0.30 \mathrm{w} / \mathrm{c}$ paste continued to hydrate at a rate greater than a companion sealed specimen.

\subsection{DSC: $100 \%$ RH exposure}

The DSC data for the SWVE specimens are considered first as a basis for analyzing the specimens exposed to $90 \%$ RH. The DSC data for the SWVE specimens are shown in Figs. 4-6 for the three w/c values. Each figure shows a series of curves, each with a label indicating the age of the specimen. The curves are offset vertically from one another and are plotted on the same ordinate scale to facilitate a direct comparison of both the relative peak heights and the corresponding freezing temperature.

Each figure gives a qualitative picture of microstructure formation during hydration under $100 \% \mathrm{RH}$ conditions, indicated by the three peaks that may appear during hydration. Fig. 4 shows that, chronologically, the first. peak appears (during the first few hours) at $-20{ }^{\circ} \mathrm{C}$ and is due to water in the capillary pores. Figures 5 and 6 reveal that the next peak forms (after 1-day hydration) at $-45^{\circ} \mathrm{C}$ and is due to water freezing in the pores with entryways only few nanometers wide. The last peak forms near $-30{ }^{\circ} \mathrm{C}$ and is due to pores of an intermediate size, which will be discussed subsequently. For this last peak, at $-30{ }^{\circ} \mathrm{C}$, the time of appearance, the time of subsequent disappearance, and the freezing temperature appear to be a function of the $w / c$ value (initial solids fraction). As mentioned previously, because the pore size distribution in the cement paste is unimodal [15], the presence of distinct peaks can only be attributed to the formation of reservoirs, composed of relatively large pores, completely

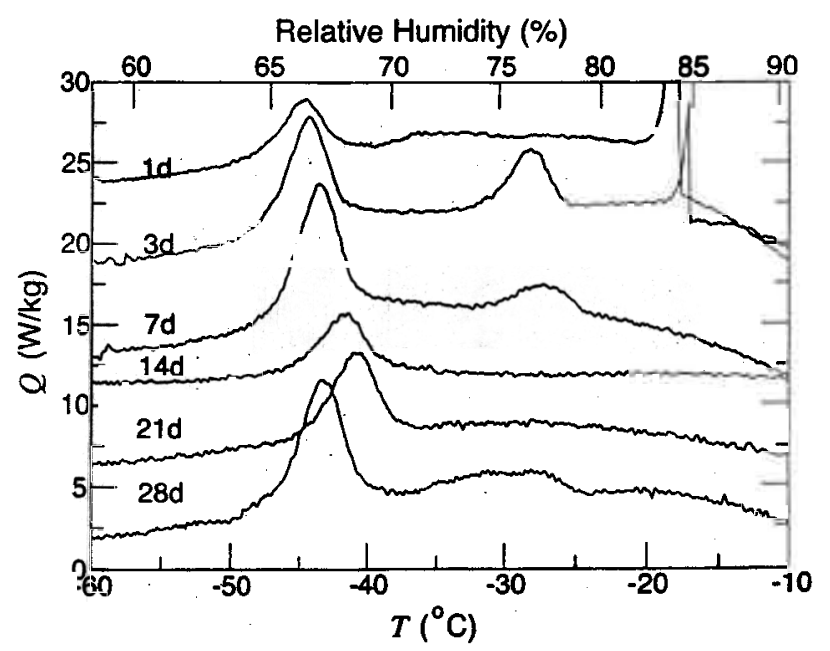

Fig. 5. Freezable water, evident as heat flow $(\mathrm{W} / \mathrm{kg})$ from the sample, as a function of time for a $0.40 \mathrm{w} / \mathrm{c}$ cement paste cured at $100 \% \mathrm{RH}$. The data labels indicate the age of the specimen since the time of casting. Individual curves are offset for comparison purposes. 


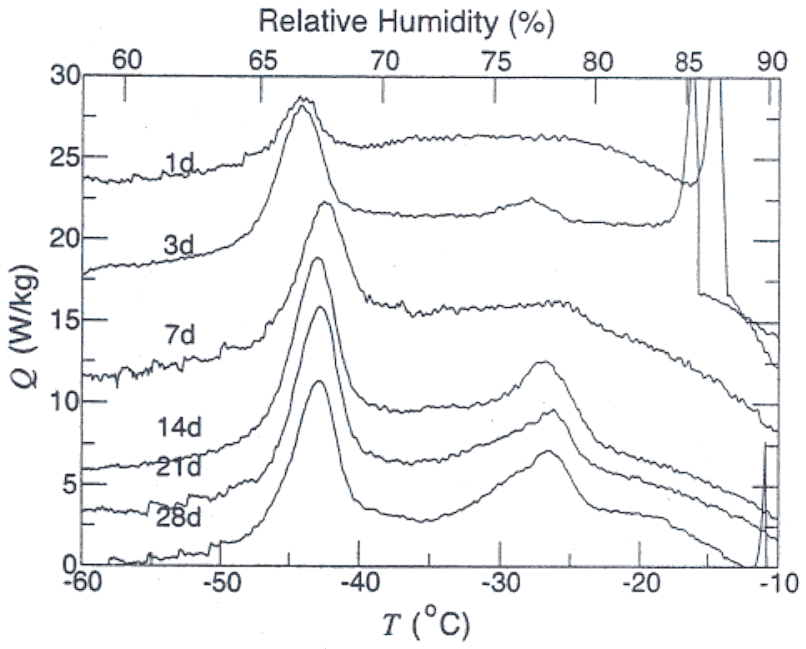

Fig. 6. Freezable water, evident as beat flow ( $\mathrm{W} / \mathrm{kg}$ ) from the sample, as a function of time for a $0.50 \mathrm{w} / \mathrm{c}$ cement paste cured at $100 \% \mathrm{RH}$. The data labels indicate the age of the specimen since the time of casting. Individual curves are offset for comparison purposes.

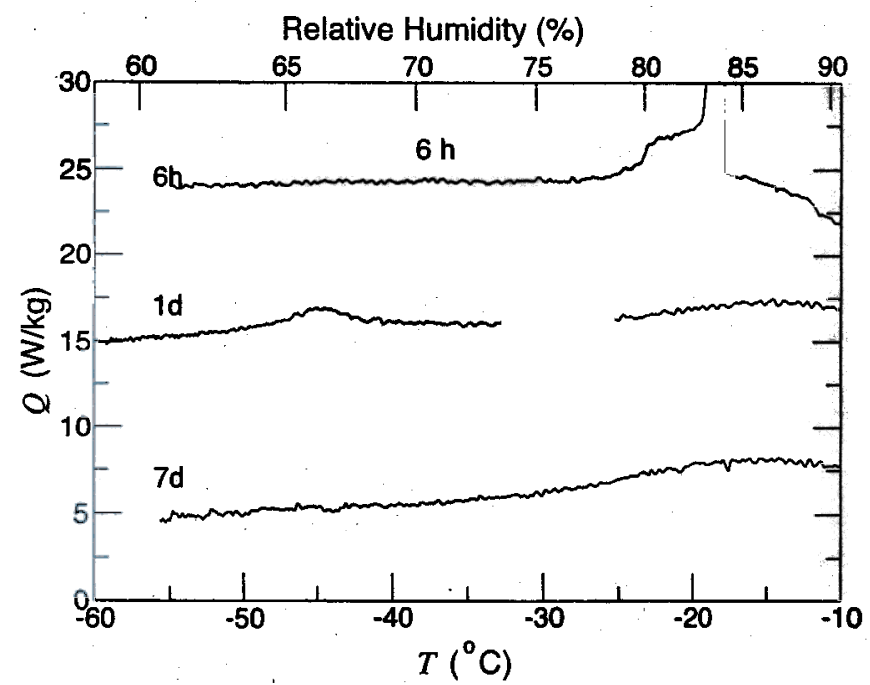

Relative Humidity (\%)

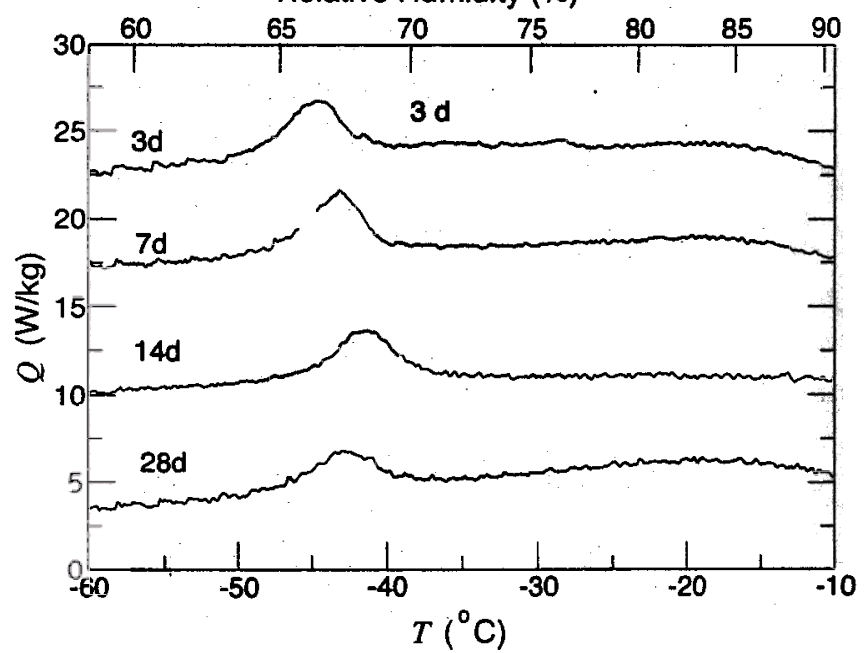

surrounded by passageways composed of relatively smaller pores.

Figs. 4-6 also include estimates for the corresponding equilibrium $\mathrm{RH}$, shown along the upper $x$ axis. The relationship between freezing temperature and equilibrium $\mathrm{RH}$ has been calculated by Fagerlund [25]. Based on the Fagerlund [25] derivation, to evaporate water from pores with a freezing peak at $-30^{\circ} \mathrm{C}$, the external $\mathrm{RH}$ at $25^{\circ} \mathrm{C}$ would have to fall below $75 \% \mathrm{RH}$. This relation, however, is only a physically motivated approximation. Moreover, because the peaks indicate the size of the pores surrounding the reservoirs, the $\mathrm{RH}$ corresponds to the equilibrium $\mathrm{RH}$ for the smaller pores surrounding the reservoir and not the equilibrium $\mathrm{RH}$ for the reservoir itself, which would be a higher RH.

An important feature of these DSC results for $100 \% \mathrm{RH}$ exposure specimens is the time-dependent behavior of the freezing peak at $-30^{\circ} \mathrm{C}$. This peak forms after the peak at $-45^{\circ} \mathrm{C}$, indicating that the pore throats that freeze at -30
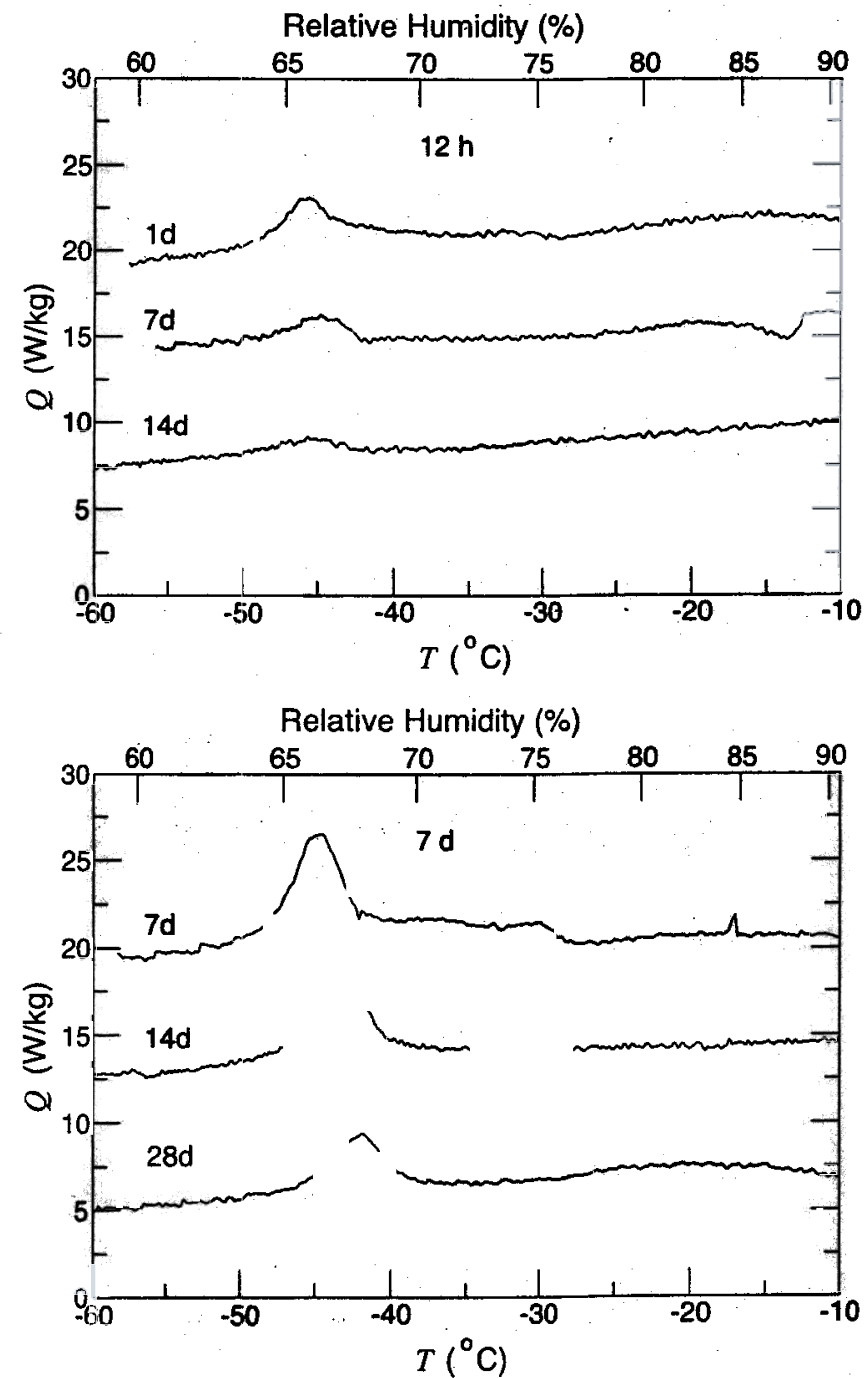

Fig. 7. Freezable water, evident as heat flow (W/kg) from the sample, as a function of time for $0.30 \mathrm{w} / \mathrm{c}$ cement paste exposed to $90 \% \mathrm{RH}$ after curing at $100 \%$ $\mathrm{RH}$ for $\mathrm{h} \mathrm{h}, 12 \mathrm{~h}, 3 \mathrm{~d}$, and $7 \mathrm{~d}$. Individual curves are offset for comparison purposes. 
${ }^{\circ} \mathrm{C}$ are the result of hydration. Moreover, the time at which the peak at $-30^{\circ} \mathrm{C}$ forms and disappears is a function of the $w / c$ value (initial solids fraction). The appearance of the $-30{ }^{\circ} \mathrm{C}$ peak occurs roughly near the age at which the capillary pores are assumed to be no longer percolated (approximately $20 \%$ capillary porosity). The disappearance of the $-30{ }^{\circ} \mathrm{C}$ peak occurs after 2 and 7 days of hydration for the 0.30 and $0.40 \mathrm{w} / \mathrm{c}$ paste, respectively. For the $0.50 \mathrm{w} /$ c paste, the $-30{ }^{\circ} \mathrm{C}$ peak formed between 7 and 14 days, and remained beyond 28 days.

In general, these results are consistent with previous results of Bager and Sellevold [26,27] on cement pastes aged for 4 months prior to DSC measurements. In that experiment, the freezing peaks located at -25 and $-45^{\circ} \mathrm{C}$ correspond to the -30 and $-45^{\circ} \mathrm{C}$ peaks, respectively, seen here; the difference is attributed to the slower freezing rate in the Bager and Sellevold [27] experiment. The Bager and Sellevold [27] data also show an absence of a $-25^{\circ} \mathrm{C}$ peak (corresponding to $-30{ }^{\circ} \mathrm{C}$ peak here) for 0.35 and $0.40 \mathrm{w} / \mathrm{c}$ pastes at 4 months of age. Similarly, the same peak remained after 4 months for pastes having a w/c equal to or greater than 0.45 .

\subsection{DSC: $90 \% R H$ exposure}

The DSC data for the samples exposed to $90 \% \mathrm{RH}$ are shown in Figs. 7-9. Each figure is composed of four graphs, one for each initial exposure time at $100 \% \mathrm{RH}$ prior to exposure to $90 \% \mathrm{RH}$, and this age is shown at the top center of the graph.

The 6- and 12-h data are quite similar for all three values of $w / c$. The peak at $-45^{\circ} \mathrm{C}$ either never forms or forms and subsequently disappears. For those specimens where the peak does occur, the age at which it appears depends upon the $w / c$ value. The peak at $-30^{\circ} \mathrm{C}$ never forms for any 6or 12-h specimen, regardless of the w/c value.
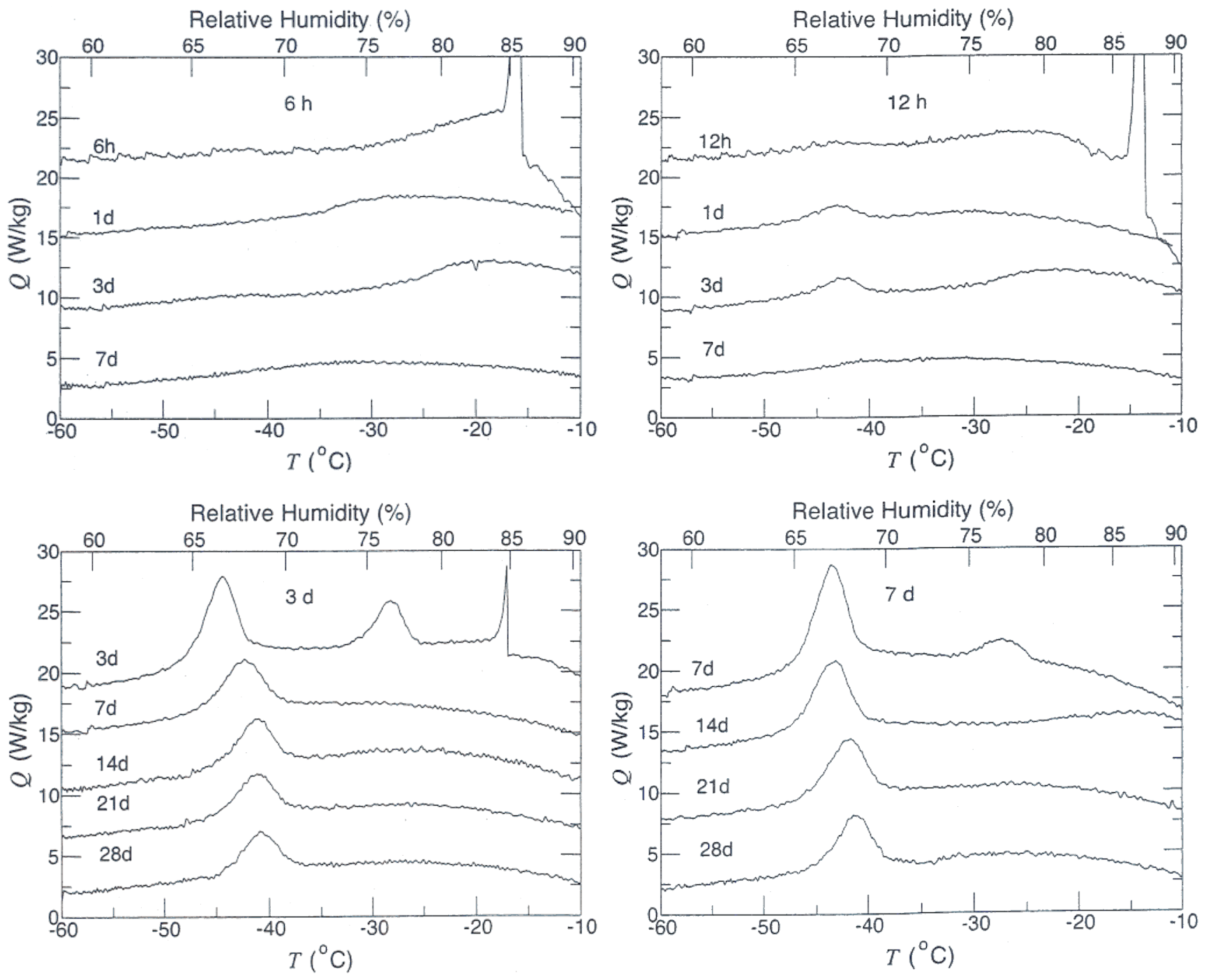

Fig. 8. Freezable water, evident as heat flow (W/kg) from the sample, as a function of time for $0.40 \mathrm{w} / \mathrm{c}$ cement paste exposed to $90 \% \mathrm{RH}$ after curing at $100 \%$ $\mathrm{RH}$ for 6 h. 12 h. 3 d. and 7 d. Individual curves are offset for comparison purposes. 

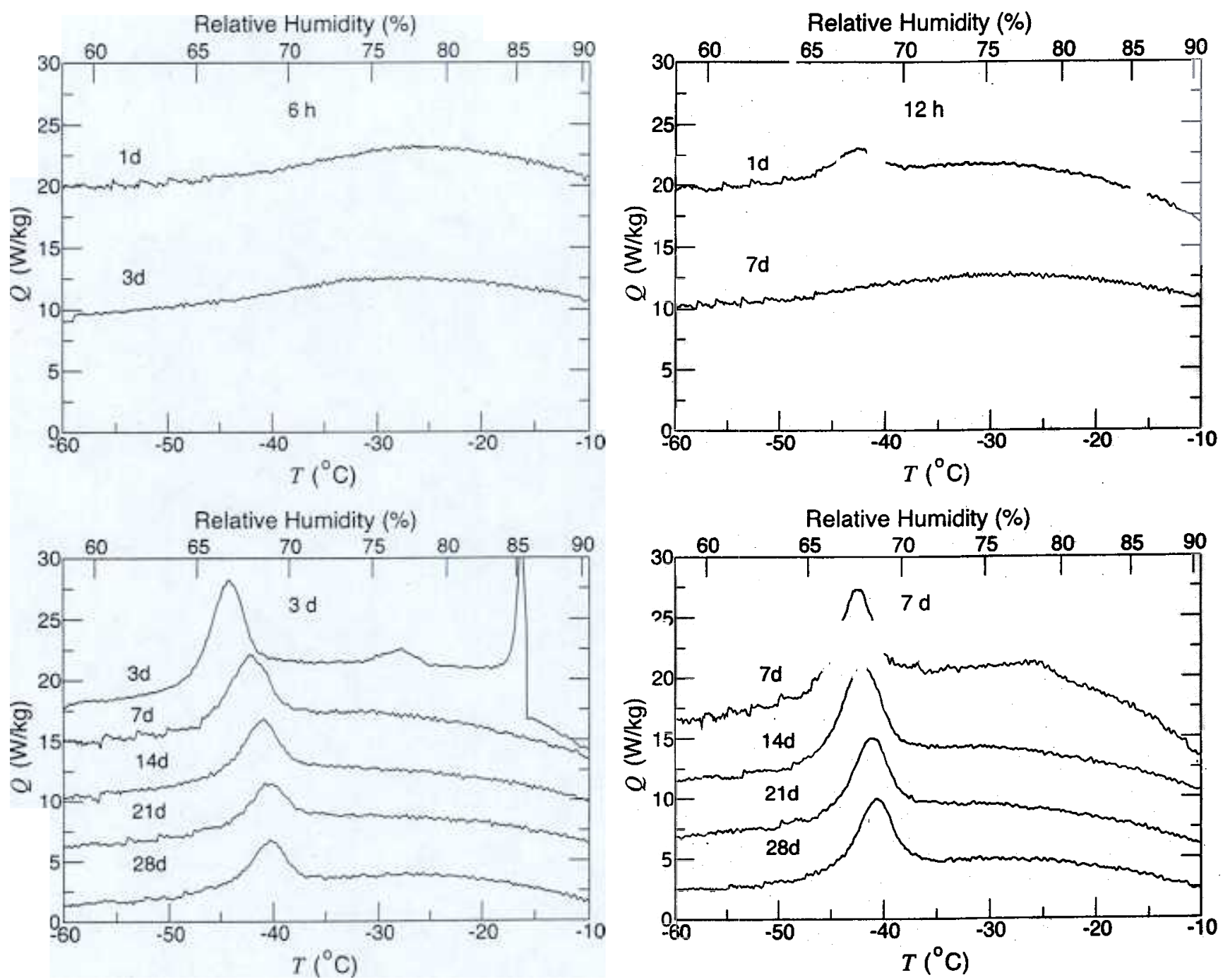

Fig. 9. Freezable water, evident as heat flow (W/ $\mathrm{kg}$ ) from the sample, as a function of time for $0.50 \mathrm{w} / \mathrm{c}$ cement paste exposed to $90 \% \mathrm{RH}$ after curing at $100 \%$ RH for $6 \mathrm{~h}, 12 \mathrm{~h}, 3 \mathrm{~d}$, and $7 \mathrm{~d}$. Individual curves are offset for comparison purposes.

For the 0.30 and $0.40 \mathrm{w} / \mathrm{c}$ pastes, the DSC data for 3 and 7 days of exposure to $90 \% \mathrm{RH}$ were as expected, based on the data from $100 \% \mathrm{RH}$ exposure specimens. The $-30^{\circ} \mathrm{C}$ peak never appears in the 3- or 7-day $0.30 \mathrm{w} / \mathrm{c}$ paste because it had already disappeared by this time in the $100 \% \mathrm{RH}$ exposure specimen. The disappearance of the $-30{ }^{\circ} \mathrm{C}$ peak in the 3- and 7-day $0.40 \mathrm{w} / \mathrm{c}$ pastes is consistent with the behavior of the SWVE specimens.

The 3- and 7-day exposure data for the $0.50 \mathrm{w} / \mathrm{c}$ paste revealed an effect of exposure on microstructural development. For the SWVE $0.5 \mathrm{w} / \mathrm{c}$ specimens, the $-30{ }^{\circ} \mathrm{C}$ peak appears after 14 days of hydration. For the samples exposed to $90 \% \mathrm{RH}$ at 3 and 7 days, the peak does not appear before the end of testing at 28 days.

Although not as dramatic, the peak at $-45^{\circ} \mathrm{C}$ appears to diminish and drift to higher temperatures over time for many of the exposed specimens. This effect is noticeable for the 6and 12-h exposures and is arguable for the 3- and 7-day specimens. Bager and Sellevold [27] observed similar effects, with the peak area decreasing noticeably for exposures below $90 \% \mathrm{RH}$ and disappearing entirely for exposures below $58 \% \mathrm{RH}$ exposure.

Regretfully, the mass of the specimens was not determined to a meaningful precision. Very small pieces of paste would stick to the mold and fall off during handling. Minor revisions to the experimental setup are needed to avoid this problem.

\section{Discussion}

The results from the $90 \% \mathrm{RH}$ exposure are sufficiently unexpected to warrant the development of a conceptual model $(\mathrm{CM})$ to explain what could be happening within the microstructure to account for the behavior. The $\mathrm{CM}$ developed here is built upon the Jennings Colloidal Model (JCM; [29]). Because the JCM is so important to the conceptual model, it will be described briefly. 


\subsection{Jennings Colloidal Model}

The behavior of both the SWVE and UWVE specimens can be explained in a manner that is consistent with the microstructural model for 1 - to $100-\mathrm{nm}$ length scales by Jennings [29] and Jennings and Tennis [30,31]. The JCM [29] identifies four types of pores, as shown in Table 2. Also shown in Table 2 are the corresponding DSC peak freezing temperatures from Valckenborg et al. [31], Bager and Sellevold [26,27], and this work.

A schematic of the JCM is shown in Fig. 10. According to the JCM, the basic unit of C-S-H is a colloidal particle having a radius on the order of $1.5 \mathrm{~nm}$. During the middle period of hydration ( 4 to $24 \mathrm{~h}$ ), these smallest units form globules. These globules, in tum, condense to form lowdensity (LD) $\mathrm{C}-\mathrm{S}-\mathrm{H}$ clusters having pores that are emptied of water only below $20 \% \mathrm{RH}$ [29]. The globules probably form first and condense to form the LD structure during the period between 10 and $24 \mathrm{~h}$ [29].

During the late period of hydration (after $24 \mathrm{~h}$ ), collections of LD C-S-H clusters aggregate to form a microstructure having inter-LD cluster pores. These pores are characterized as being full of water at $90 \% \mathrm{RH}$ and empty by $40 \% \mathrm{RH}$ [29]. Therefore, the JCM is consistent with the DSC results for SWVE specimens, assuming that the -45 ${ }^{\circ} \mathrm{C}$ peak corresponds to water within the LD C-S-H pores and the $-30{ }^{\circ} \mathrm{C}$ peak corresponds to water that is only accessible via the inter-LD pores. These freezing temperatures are denoted in the schematic in Fig. 10.

The JCM forms a foundation for understanding the DSC results for the $100 \% \mathrm{RH}$ exposure. From the JCM and the DSC results, a self-consistent CM is developed to explain the observations. The $\mathrm{CM}$ is first developed based on the SWVE specimens and then used to explain the DSC results for the UWVE specimens.

\subsection{CM: $100 \%$ RH environment}

Here, it is conjectured that the inter-LD C-S-H forms on the walls of both the capillary pores and the intercapil-

Table 2

Summary of pore size classes and approximate DSC pore freezing temperature $T_{m}$

\begin{tabular}{|c|c|c|c|c|c|}
\hline \multirow[t]{2}{*}{ Pore class } & \multirow{2}{*}{$\frac{\text { Pore size }(\mathrm{nm})}{(\mathbf{a}, \mathbf{b})}$} & \multirow{2}{*}{ Description } & \multicolumn{3}{|c|}{$T_{m}\left({ }^{\circ} \mathrm{C}\right)$} \\
\hline & & & & (c) & (d) \\
\hline $\mathrm{C}-\mathrm{S}-\mathrm{H}$ Gel & - & Chemically bound & - & & \\
\hline Mono-layer & $0.25-0.45$ & Globule pores & -70 & & \\
\hline Dense gel & 1.2 & $\begin{array}{l}\text { Interglobule pores } \\
\text { within LD structure }\end{array}$ & -60 & -45 & -45 \\
\hline Open gel & $1-10$ & $\begin{array}{l}\text { Pores between LD } \\
\text { and HD units }\end{array}$ & -20 & -25 & -30 \\
\hline Capillary & $>10$ & Larger than gel pores & -10 & -10 & -20 \\
\hline
\end{tabular}

(a) Valckenborg et al. [31].

(b) Jennings [29].

(c) Bager and Sellevold $[26,27]$

(d). This work.

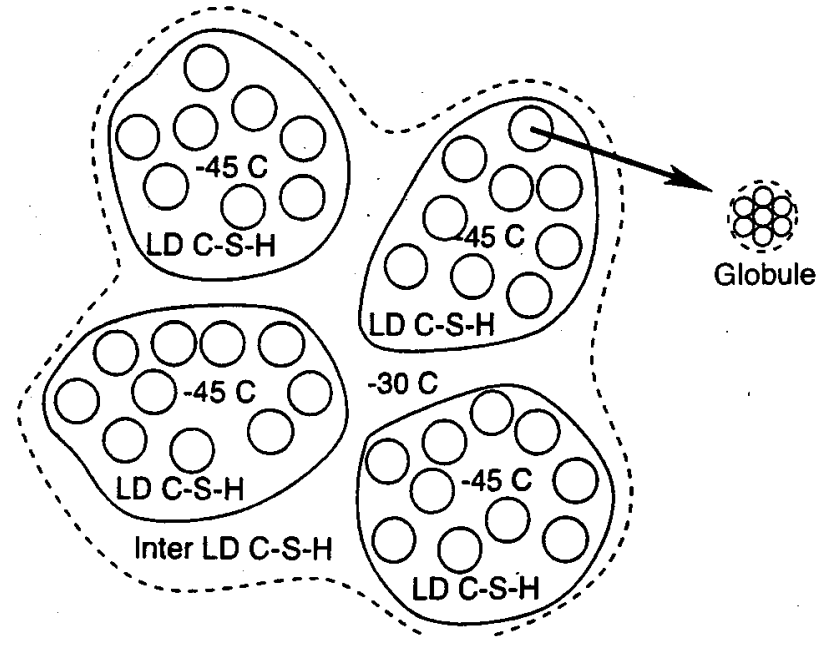

Fig. 10. Schematic of JCM. LD C-S-H is composed of globules, and the interglobule pores freeze at $-45^{\circ} \mathrm{C}$. The Inter $\mathrm{LD} \mathrm{C}-\mathrm{S}-\mathrm{H}$ microstructure is composed of $\mathrm{LD} \mathrm{C}-\mathrm{S}-\mathrm{H}$ clusters, and the inter $\mathrm{LD} \mathrm{C}-\mathrm{S}-\mathrm{H}$ pores freeze at $-30^{\circ} \mathrm{C}$.

lary spaces, and a schematic of the $\mathrm{CM}$ is shown in Fig. 11. Initially, the inter-LD C-S-H thickness is far smaller than either the capillary pores or the intercapillary spaces. As a result, for water to freeze within the capillary pores, the advancing ice front has to penetrate only the intercapillary pore space, manifesting itself as a DSC peak at $-20^{\circ} \mathrm{C}$. This situation is depicted in Fig. 11(a).

Upon further hydration, the inter-LD C-S-H continues to fill both the capillary pores and the intercapillary spaces. Eventually, the intercapillary pore space becomes filled with inter-LD $\mathrm{C}-\mathrm{S}-\mathrm{H}$, and the capillary pores are no longer percolated via the intercapillary pore space. For water to freeze within the existing capillary pores, the advancing ice front must now pass through the inter-LD $\mathrm{C}-\mathrm{S}-\mathrm{H}$ pores. As a result, DSC data no longer exhibit a peak at $-20{ }^{\circ} \mathrm{C}$, but at $-30{ }^{\circ} \mathrm{C}$ instead. This situation is depicted in Fig. 11(b). Unfortunately, in this experiment, measures were not taken to eliminate supercooled surface water through the use of silver iodide [28]; thus, the

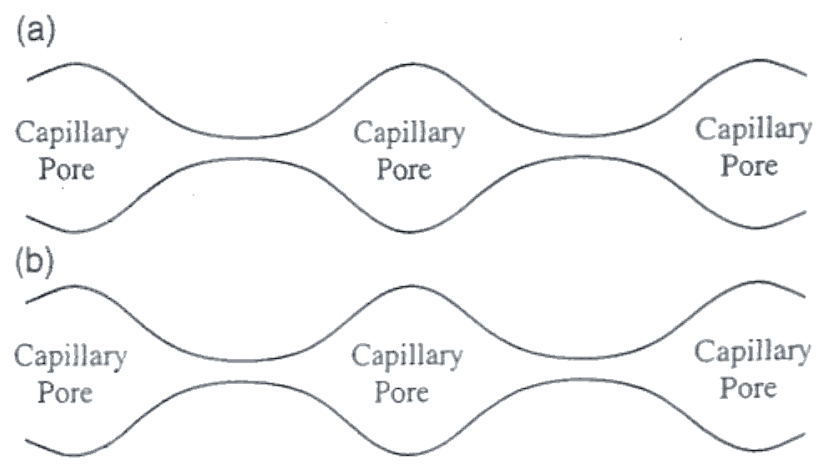

Fig. 11. Schematic of capillary pores, each lined with Inter-LD C-S-H. (a) Capillary pores are continuous. (b) Capillary pores are accessible only via regions filled with Inter-LD C-S-H. 
physical interpretation of the $-20{ }^{\circ} \mathrm{C}$ peaks cannot be stated definitively in this experiment.

As seen in Figs. 1-3, the 20\% capillary porosity (based on Eq. (2)) and the appearance of the $-30{ }^{\circ} \mathrm{C}$ peak give different estimates for the age at which the capillary pores are no longer percolated. There are a number of explanations for this difference. In a pixel-based model, percolation is a well-defined quantity and has a binary value. By contrast, in a hydrating cement paste, there is a critical pore diameter $d_{c}$ [32] that, conceptually, defines the diameter of the largest sphere that can pass through the system. For these systems, there will always be a critical pore diameter, even if the length scale of $d_{\mathrm{c}}$ must approach atomic dimensions; hence, there is no definite point at which porosity is no longer percolated. Therefore, in cementitious systems, percolation can only be defined with respect to a given threshold pore diameter.

In addition, the permeability of the system can be approximated by $d_{c}^{2}$ [32]. If at early ages, the critical capillary pore diameter has dimensions of micrometers, the permeability has a value that is on the order of $10^{-12}$ $\mathrm{m}^{2}$. When the $-30{ }^{\circ} \mathrm{C}$ peak appears, the critical pore diameter has decreased to the range $1-10 \mathrm{~nm}$, and the permeability has fallen to approximately $10^{-18} \mathrm{~m}^{2}$, which is typical for cementitious systems. This is consistent with the dramatic change in permeability that Powers et al. [21] originally observed and attributed to the cessation of capillary pore percolation.

There are three possible explanations for the subsequent disappearance of the $-30^{\circ} \mathrm{C}$ peak: loss of water from the capillary pores, collapse (and densification) of the phase containing the inter-LD C-S-H pores, or the cessation of percolation of the inter-LD C-S-H phase. The loss of water from the capillary pores (due to hydration) is unlikely to occur within 7 days in a SWVE $0.40 \mathrm{w} / \mathrm{c}$ paste (the age at which the $-30^{\circ} \mathrm{C}$ peak disappears in this experiment). Given that the SWVE specimens hydrated at virtually the same rate as the saturated specimens did, water imbibition through chemical shrinkage probably occurred at a sufficient rate to keep the pores saturated with water. Alternatively, a physical collapse of the inter-LD C-S-H phase would suggest a freezing peak near $-30^{\circ} \mathrm{C}$ that slowly moves toward lower temperatures, but this was not observed here.

The cessation of inter-LD C-S-H pore percolation is plausible if continued hydration could fill in the inter-LD pores with a regular microstructure, possibly LD $\mathrm{C}-\mathrm{S}-\mathrm{H}$, until the freezable capillary pore water is only accessible via the LD C-S-H pores, similar with the argument for the appearance of the $-30^{\circ} \mathrm{C}$ peak. If this were to happen, available freezable water would not freeze until $-45^{\circ} \mathrm{C}$, as was observed. The rate at which this occurs would also depend on the initial solids fraction (w/c), as was also observed in this experiment.

The disappearance of the $-30{ }^{\circ} \mathrm{C}$ peak in the SWVE specimens suggests the critical pore diameter $d_{c}$ decreases from the size of the inter-LD pores $(1-10 \mathrm{~nm})$ down to the size of LD C-S-H pores (approximately $1.2 \mathrm{~nm}$ ). The corresponding decrease in permeability would be one to two orders of magnitude. Based on this assumption, extremely low-permeability concretes can only be achieved in those systems for which the $-30^{\circ} \mathrm{C}$ peak has disappeared.

Upon studying Figs. 1-3, the disappearance of the -30 ${ }^{\circ} \mathrm{C}$ freezing peak appears to coincide with the age at which the capillary porosity is approximately equal to $20 \%$. One could argue that the disappearance of the $-30{ }^{\circ} \mathrm{C}$ peak corresponds to a significant reduction in the critical pore diameter $d_{\mathrm{c}}$ and accounts for the dramatic change in permeability that Powers et al. [21] based their conclusions on. The agreement between the age when the peak first appears and the predicted minimum curing duration by Powers et al. [21] may have only been coincidental, attributed to the changes in cement production in the intervening decades. The only definitive way to resolve this question would be to perform simultaneous DSC and permeability measurements.

\subsection{CM: $90 \%$ RH environment}

The analysis of the UWVE specimens can now be formulated in the context of the CM for SWVE specimens. For the specimens exposed to $90 \% \mathrm{RH}$, the primary difference is the loss of freezable water within the pores.

The water loss was most evident in the specimens exposed to $90 \% \mathrm{RH}$ at a young age. For all values of $\mathrm{w} / \mathrm{c}$, the UWVE specimens at 6 and $12 \mathrm{~h}$ never exhibited a freezing peak at $-30{ }^{\circ} \mathrm{C}$. Moreover, those 6- and 12h specimens that formed a peak at $-45^{\circ} \mathrm{C}$ eventually lost all the water from those pores. The loss of water from the $-45^{\circ} \mathrm{C}$ peak indicates that upon consumption of all the available free water, the chemical driving force for hydration is sufficient to extract water from the reservoirs surrounded by LD C-S-H pores.

The 3- and the 7-day data for the 0.3 and $0.4 \mathrm{w} / \mathrm{c}$ pastes were, in general, consistent with the data from the SWVE specimens. Because the $-30{ }^{\circ} \mathrm{C}$ peak had disappeared prior to 3 days for SWVE $0.3 \mathrm{w} / \mathrm{c}$ pastes, the paste was sufficiently able to retain moisture to continue hydrating at a rate equal to that of a sealed specimen. As has been observed from chemical shrinkage measurements, as impermeable as the SWVE 3-day $0.3 \mathrm{w} / \mathrm{c}$ paste is, it is still able to absorb moisture in a $100 \% \mathrm{RH}$ environment. This accounts for the difference in the hydration rate between the 3- and the 7-day $0.3 \mathrm{w} / \mathrm{c}$ pastes.

The 3-day $0.4 \mathrm{w} / \mathrm{c}$ paste, having only just formed the $-30{ }^{\circ} \mathrm{C}$ peak, was still able to lose water to the environment (the rate of hydration was slower than that for a sealed specimen) because a sufficient volume of capillary pores was not surrounded by inter-LD pores. The 7 -day $0.4 \mathrm{w} / \mathrm{c}$ paste (being under similar conditions, with respect to the $-30{ }^{\circ} \mathrm{C}$ peak, as the 3-day $0.3 \mathrm{w} / \mathrm{c}$ paste) continued to hydrate at a rate equal to a sealed specimen, which is identical to SWVE specimen at this w/c value.

The 3- and 7-day $0.5 \mathrm{w} / \mathrm{c}$ paste data highlight different aspects of cement hydration. For both cases, the $-30{ }^{\circ} \mathrm{C}$ 
peak has not formed at the time of exposure. Based on previous arguments, the capillary pores are sufficiently percolated to lose a large quantity of evaporable water. Interestingly, both the 3 - and 7-day $0.5 \mathrm{w} / \mathrm{c}$ pastes continued hydrating at a measurable rate. Although some capillary water was probably lost from both systems, it appears as though that hydration continued by consuming water trapped in the $\mathrm{LD} \mathrm{C}-\mathrm{S}-\mathrm{H}$ pores that freeze at $-45^{\circ} \mathrm{C}(6-$ and $12-$ $h$ DSC data demonstrate that hydration can remove water from these pores). In fact, the $-45^{\circ} \mathrm{C}$ peak heights for both the 3- and 7-day systems appear to decrease. The fact that the 7-day system is able to hydrate at the same rate as an SWVE system is not altogether surprising because higher w/c pastes contain greater volumes of water in the $\mathrm{LD} \mathrm{C}-\mathrm{S}-\mathrm{H}$ pores that freeze at $-45^{\circ} \mathrm{C}[33]$.

\subsection{Implications: Microstructure development}

The absence of the $-30{ }^{\circ} \mathrm{C}$ peak on the 3- and 7-day exposures for the $0.5 \mathrm{w} / \mathrm{c}$ specimen raises questions regarding microstructure formation under UWVE. Although DOH data exhibit only a minor effect due to the exposure, the DSC data suggest that the microstructure might be considerably different. The absence of the freezing peak at $-30{ }^{\circ} \mathrm{C}$ indicates that either capillary pores remained percolated or the capillary pores were enclosed by inter-LD C-S-H, but no water remained within the capillary pores. Regardless, given evidence that the pastes hydrated at lower relative humidities exhibited higher levels of silicate polymerization [34], that the observed $-45{ }^{\circ} \mathrm{C}$ peak height decreased, and that the amount of bound water is proportional to the amount of free water $[26,33]$, it is quite likely that the final microstructure of the $0.50 \mathrm{w} / \mathrm{c} 3-$ and 7 -day specimens at 28 days are different from the corresponding saturated specimens. Evidence to this effect for $0.4 \mathrm{w} / \mathrm{c}$ mortars can be found in the Bager experiment [7]. Using the diffusion coefficient of 14 days of curing as a reference, Bager [7] found that the diffusion coefficient of specimens cured for 2 and 7 days were a factor of 3 and 2 greater, respectively.

Moreover, simply rewetting a paste that has been exposed prior to the formation of the $-30^{\circ} \mathrm{C}$ peak might not negate any detrimental effects. Based on rewetting experiments on 0.40 and $0.60 \mathrm{w} / \mathrm{c}$ pastes [27], water loss in both the -30 and $-45^{\circ} \mathrm{C}$ peaks is not recovered upon rewetting, even though the total initial evaporable water content was nearly fully recovered upon rewetting.

\subsection{Implications: Curing}

The practical result of this experiment may be a means of determining the minimum required curing duration, depending upon the performance criterion. Based solely on the DOH data, one would conclude that the minimum duration of curing is 7 days, regardless of $w / c$ value, for these are the only UWVE specimens that hydrated at a rate equivalent to a specimen. This recommendation would agree with $\mathrm{ACI}$ 308 guidelines.

If the criterion changes from observed $\mathrm{DOH}$ to microstructure and durability performance, the fixed 7-day curing may be too burdensome for lower w/c pastes and insufficient for higher w/c pastes. Delaying the exposure to an unsaturated environment until the $-30{ }^{\circ} \mathrm{C}$ peak first appears would ensure, at the very least, proper microstructural development. Based on these experimental results, the minimum curing at $25^{\circ} \mathrm{C}$ for the $0.30,0.40$, and $0.50 \mathrm{w} / \mathrm{c}$ ordinary portland cement pastes are approximately at 1,3 , and 14 days of saturated curing, respectively. Remarkably, these recommendations agree with the recommendations of Powers et al. [21] that were made nearly 45 years ago.

\section{Conclusion}

The effect of an unsaturated water vapor environment on the rate of cement paste hydration depends on the duration of the initial hydration under saturated conditions. The minimum duration of curing required to meet performance objectives depends upon the specific performance criterion. When the performance criterion is a rate of hydration equal to that of a continuously saturated specimen, the minimum curing time appears to be 7 days for all w/c values ranging from 0.3 to 0.5 . When the criterion is microstructural development, the time required for the paste to develop a sufficiently dense microstructure, to mitigate the effects of exposure, appears to coincide with the formation of a DSC freezing peak near $-30^{\circ} \mathrm{C}$. For the $0.30,0.40$, and $0.50 \mathrm{w} /$ c pastes studied here, the $-30^{\circ} \mathrm{C}$ peak forms at 1,3 , and 14 days, respectively. Arguably, the disappearance of the $-30{ }^{\circ} \mathrm{C}$ peak may be a more reliable indicator of microstructural development, but further experiments are needed to justify this. A colloidal microstructural model is used to argue that the appearance of the $-30{ }^{\circ} \mathrm{C}$ freezing peak coincides with the time at which the capillary pores are no longer percolated. Consistent with this hypothesis, samples exposed to $90 \% \mathrm{RH}$ after the appearance of the $-30{ }^{\circ} \mathrm{C}$ freezing peak continued to hydrate at a rate equal to, or greater than, the rate of hydration under sealed conditions. As a result, the observation of the DSC freezing peak at $-30{ }^{\circ} \mathrm{C}$ in ordinary portland cement concretes is a likely candidate for the development of a field test for the minimum duration of curing required to ensure that subsequent exposure to an unsaturated environment will have little effect on the microstructural development.

\section{Acknowledgements}

The authors wish to acknowledge the helpful comments and suggestions by Prof. Hamlin Jennings of Northwestem University, and for the additional comments and discussion 
by Dr. Jeffrey Bullard of the Building and Fire Research Laboratory (NIST).

The authors also wish to acknowledge the journal reviewers, whose thoughtful comments contributed to the quality of the paper.

\section{References}

[1] H.F.W. Taylor, Cement Chemistry, Academic Press, New York, 1990.

[2] Standard Practice for Curing Concrete (ACI 308-92), ACI Manual of Practice, American Concrete Institute, Detroit, MI, 2001, pp. 308-301.

[3] T.C. Powers, A discussion of cement hydration in relation to the curing of concrete, Proc. Highw. Res. Board 27 (1947) 178-188.

[4] G.R. Gause, J. Tucker Jr., Method for determining the moisture condition in hardened concrete, J. Res. Natl. Bur. Stand. 25 (1940) $403-416$.

[5] A.W. Adamson, Physical Chemistry of Surfaces, Fifth Edition, WileyInterscience, New York, 1990.

[6] L.J. Parrott, D.C. Killoh, R.G. Patel, Cement hydration under partially saturated curing conditions, 8th International Congress on the Chemistry of Cement, Rio de Janeiro, 1986, pp. 46-50.

[7] D.H. Bager, Effect of curing on the pore structure and permeability of cement-flyash mortars, Proceedings of the RILEM Seminar on the Durability of Concrete Structures Under Normal Outdoor Exposure, Hannover, Germany, 1984, pp. 102-115.

[8] R.K. Haupt, Final Report: Portland Cement Proficiency Samples Number 115 and Number 116, Cement and Concrete Reference Laboratory, Gaithersburg, MD, 1995.

[9] S. Hasegawa, J.W. Little, The NBS two-pressure humidity generator: Mark 2, J. Res. Natl. Bur. Stand. 81A (1977) 81-88.

[10] T.C. Powers, The nonevaporable water content of hardened portlandcement paste-its significance for concrete research and its method of determination, ASTM Bull. 158 (1949) 68-76.

[11] F. Radjy, E.J. Sellevold, C.W. Richards, Effect of freezing on the dynamic mechanical response of hardened cement paste down to $-60^{\circ} \mathrm{C}$, Cem. Concr. Res. 2 (1972) 697-715.

[12] C. le Sage de Fontenay, E.J. Sellevold, Ice formation in hardened cement paste: I. Mature water-saturated pastes, in: P.J. Sereda, G.G. Litvan (Eds.), Durability of Building Materials and Component (ASTM STP 691), American Society for Testing and Materials, Philadelphia, PA, 1980, pp. 425-438.

[13] A. Damasceni, L. Dei, E. Fratini, F. Ridi, S.-H. Chen, P. Baglioni, A novel approach based on differential scanning calorimetry applied to the study of tricalcium silicate hydration kinetics, J. Phys. Chem., B 106 (2002) 11572-11578.

[14] C.L. Jackson, G.B. McKenna, The melting behavior of organic materials confined in porous solids, J. Chem. Phys. 93 (1990) 9002-9011.

[15] E.J. Sellevold, D.H. Bager, Low temperature calorimetry as a pore structure probe, 7th International Congress on the Chemistry of Cement, Paris, vol. 4; 1981, pp. 394-399.

[16] T. Knudsen, 7th International Congress on the Chemistry of Cement, Paris vol 2, (1981) 170-175.
[17] M. Geiker, Studies of Portland Cement Hydration by Measurements of Chemical Shrinkage and Systematic Evaluation of Hydration Curves by Means of the Dispersion Model, PhD Dissertation, Technical University of Denmark, 1983, p. 259.

[18] N.J. Carino, Applicability of the Maturity Method to High-performance Concrete (NISTIR 4819), National Institute of Standards and Technology, U.S. Department of Commerce, Gaithersburg, MD, 1992 (May), p. 62.

[19] D.P. Bentz, K.A. Snyder, and P.E. Stutzman, Hydration of portland cement: The effects of curing conditions, in: H. Justnes (Ed.), Proceedings of the 10th International Conference on Cement Chemistry, vol. 2, Sweden, 1997, Paper 2:078.

[20] D.P. Bentz, K.A. Snyder, P.E. Stutzman, Microstructural modelling of self-desiccation during hydration, in: B. Persson, G. Fagerlund (Eds.), Proceedings of an International Research Seminar in Lund, Self-Desiccation and Its Importance in Concrete Technology, 1997, pp. $132-140$.

[21] T.C. Powers, L.E. Copeland, H.M. Mann, Capillary continuity or discontinuity in cement paste, PCA Bull. 10 (1959) 2-12.

[22] D.P. Bentz, E.J. Garboczi, Percolation of phases in a three-dimensional cement paste microstructural model, Cem. Concr. Res. 21 (1991) $325-344$.

[23] E.J. Garboczi, D.P. Bentz, The effect of statistical fluctuation, finite size error, and digital resolution on the phase percolation and transport properties of the NIST cement hydration model, Cem. Concr. Res. 31 (2001) $1501-1514$.

[24] J.F. Young, W. Hansen, Volume relationships for $\mathrm{C}-\mathrm{S}-\mathrm{H}$ formation based on bydration stoichiometries, in: L.J. Struble, P.W. Brown (Eds.), Microstructural Development During Hydration of Cement, Mat. Res. Soc. Symp. Proc., vol. 85, 1987, pp. 313-322.

[25] G. Fagerlund, Determination of pore-size distribution from freezingpoint depression, Mater. Constr. 6 (1973) 215-225.

[26] D.H. Bager, E.J. Sellevold, Ice formation in hardened cement paste: Part 1. Room temperature cured pastes with variable moisture contents, Cem. Concr. Res. 16 (1986) 709-720.

[27] D.H. Bager, E.J. Sellevold, Ice formation in hardened cement paste: Part 2. Drying and resaturation on room temperature cured pastes, Cem. Concr. Res. 16 (1986) 835-844.

[28] H.M. Jennings, A model for the microstructure of calcium silicate hydrate in cement paste, Cem. Concr. Res. 30 (2000) 101-116.

[29] H.M. Jennings, P.D. Tennis, Model for developing microstructure in portland cement pastes, J. Am. Ceram. Soc. 77 (1994) 3161-3172 (and correction J. Am. Ceram. Soc. 78 (1995) 2575).

[30] P.D. Tennis, H.M. Jennings, A model for two types of calcium silicate hydrate in the microstructure of portland cement pastes, Cem. Concr. Res. 30 (2000) 855-863.

[31] R.M.E. Valckenborg, L. Pel, K. Kopinga, Combined NMR cryoporometry and relaxometry, J. Phys., D, Appl. Phys. 35 (2002) 249-256.

[32] A.J. Katz, A.H. Thompson, Quantitative prediction of permeability in porous rocks, Phys. Rev., B 34 (1986) 8179-8181.

[33] M. Rossler, I. Odler, Investigations on the relationships between porosity, structure and strength of hydrated portland cement pastes: 1. Effect of porosity, Cem. Concr. Res. 15 (1985) 320-330.

[34] D.E. Macphee, E.E. Lachowski, F.P. Glasser, Polymerization effects in C-S-H: implications for portland cement hydration, Adv. Cem. Res. 1 (1988) 131-137. 